\title{
Molecular Analysis of the Role of the Group A Streptococcal Cysteine Protease, Hyaluronic Acid Capsule, and M Protein in a Murine Model of Human Invasive Soft-Tissue Infection
}

\author{
Cameron D. Ashbaugh, ${ }^{\star \ddagger}$ Henry B. Warren, ${ }^{\S}$ Vincent J. Carey, ${ }^{\star}$ and Michael R. Wessels ${ }^{\star \ddagger}$ \\ *Channing Laboratory, Brigham and Women’s Hospital, ${ }^{\ddagger}$ Division of Infectious Diseases, Beth Israel Deaconess Medical Center, ${ }^{\S}$ Center \\ for Animal Resources and Comparative Research, and Harvard Medical School, Boston, Massachusetts 02115
}

\begin{abstract}
Human invasive soft-tissue infections caused by group A Streptococcus are associated with significant morbidity and mortality. To investigate the pathogenesis of these serious infections, we characterized the host response to bacterial challenge with an M-type 3 isolate recovered from a patient with necrotizing fasciitis, or with isogenic gene replacement mutants deficient in cysteine protease, hyaluronic acid capsule, or $\mathrm{M}$ protein in a murine model of human invasive soft-tissue infection. Animals challenged with the wild-type or cysteine protease-deficient strain developed spreading tissue necrosis at the site of inoculation, became bacteremic, and subsequently died. Histopathologic examination of the necrotic lesion revealed bacteria throughout inflamed subcutaneous tissue. Arterioles and venules in the subcutaneous layer were thrombosed and the overlying tissue was infarcted. In contrast, animals challenged with either an acapsular or M protein-deficient mutant developed a focal area of tissue swelling at the site of inoculation without necrosis or subsequent systemic disease. Histopathologic examination of the soft-tissue lesion demonstrated bacteria confined within a well-formed subcutaneous abscess. We conclude that the group A streptococcal hyaluronic acid capsule and $M$ protein, but not the cysteine protease, are critical for the development of tissue necrosis, secondary bacteremia, and lethal infection in a murine model of human necrotizing fasciitis. (J. Clin. Invest. 1998. 102:550560.) Key words: Streptococcus pyogenes • necrotizing fasciitis • virulence
\end{abstract}

\section{Introduction}

Serious group A streptococcal (GAS) ${ }^{1}$ infections frequently involve bacterial invasion from the skin or mucosal surface to a normally sterile body site. Clinical manifestations of invasive disease include isolated bacteremia, skin and soft-tissue infec-

Address correspondence to Cameron D. Ashbaugh, Channing Laboratory, 181 Longwood Avenue, Boston, MA 02115. Phone: 617-5252242; FAX: 617-731-1541; E-mail: cashbaugh@channing.harvard.edu

Received for publication 10 February 1998 and accepted in revised form 5 June 1998 .

1. Abbreviations used in this paper: GAS, group A Streptococcus; THY, Todd-Hewitt broth supplemented with yeast extract.

J. Clin. Invest.

(C) The American Society for Clinical Investigation, Inc. 0021-9738/98/08/0550/11 \$2.00

Volume 102, Number 3, August 1998, 550-560

http://www.jci.org tion, septic arthritis, pneumonia, and meningitis. A recent population-based, prospective study in Ontario, Canada determined the annual incidence of GAS invasive infection to be 1.5 cases in 100,000 persons (1). M-type 1 and M-type 3 strains have been responsible for the majority of invasive infections in recent surveys $(2,3)$, although many serotypes appear to be capable of causing disease $(1,4)$. Especially virulent soft-tissue infections are characterized by rapidly spreading tissue necrosis, often with secondary bacteremia $(1,5,6)$. The clinical course of these infections suggests that GAS express spreading factors that mediate host-tissue damage leading to extension of the local infection and systemic bacterial dissemination.

Hyaluronidase, DNase, and streptokinase are all GAS products that may function as spreading factors. In addition, recent work has focused on the role of an extracellular cysteine protease encoded by speB, which has been postulated to promote degradation of ground substance via activation of a host collagenase $(7,8)$. Epidemiologic studies have linked protease production to necrotizing infection $(9,10)$. Supporting the epidemiologic association between protease expression and invasive infection are the experiments of Lukomski et al. in which GAS M3 and GAS M49 cysteine protease-deficient mutants were attenuated in their ability to cause bacteremia and lethal infection in mice after intraperitoneal challenge $(11,12)$. These results suggest that cysteine protease production may be an important virulence factor in invasive GAS disease.

In the process of local invasion and systemic spread, GAS must resist opsonophagocytic killing, the major host clearance mechanism for extracellular bacterial pathogens. GAS produce two cell surface molecules, the hyaluronic acid capsule and $M$ protein, that appear to be critical for resisting opsonophagocytosis. Evidence supporting the antiphagocytic effect of the capsule is substantial. In contrast to isogenic acapsular mutants, encapsulated organisms are resistant to phagocytic killing both in human blood and in $10 \%$ human serum (13). The ability of encapsulated organisms to resist opsonophagocytosis in vitro is correlated with increased virulence in vivo. In murine models of human GAS infection, encapsulated strains were significantly more virulent than isogenic acapsular mutants after intraperitoneal, intranasal, or subcutaneous challenge (13-16).

$\mathrm{M}$ protein also mediates GAS resistance to opsonophagocytic killing in vitro $(17,18)$, although linking $M$ protein expression with GAS virulence in vivo has been difficult. Lancefield noted that mouse-virulent GAS strains invariably expressed $\mathrm{M}$ protein, whereas $\mathrm{M}$ protein expression in avirulent strains was less consistent (19). Hollingshead et al. found that strains deficient in M6 protein were less effective in longterm colonization of the rat pharynx than the parent strains expressing M6 protein (20). However, Husmann et al. found no differences either in long-term colonization or pneumonia in mice challenged intranasally with the wild-type strain or an isogenic M50 deletion mutant (15), and Moses et al. demon- 
strated only a modest decrease in mortality in mice challenged intraperitoneally with an M18 knockout mutant (21). Thus, although there is good evidence that $\mathrm{M}$ protein is involved in evasion of phagocytic killing in vitro, the data remain inconclusive with respect to the role of $\mathrm{M}$ protein in bacterial virulence during in vivo infection.

In addition to the hyaluronic acid capsule and $\mathrm{M}$ protein that directly inhibit opsonophagocytosis, the GAS C5a peptidase and cysteine protease may contribute to bacterial evasion of host clearance by impairing recruitment of phagocytes to sites of infection. The GAS C5a peptidase inactivates the complement component C5a, a potent chemoattractant for neutrophils $(22,23)$. Release of the peptidase from the bacterial surface is in part mediated by the cysteine protease (24). Mice challenged intraperitoneally with a cysteine protease-deficient GAS mutant were more efficient in recruiting polymorphonuclear cells to the peritoneum and more effective in clearing bacteria from the peritoneum than animals challenged with the parent strain that expressed the protease (12).

To investigate the role of the cysteine protease, hyaluronic acid capsule, and $M$ protein in the pathogenesis of GAS invasive soft-tissue infection, we used gene replacement mutagenesis to derive cysteine protease-deficient, acapsular, and M protein-deficient mutants from a GAS M3 strain isolated from a child with necrotizing fasciitis and tested the mutants for their ability to cause disease in a murine model of human necrotizing soft-tissue infection (16). Our results demonstrate that loss of either the hyaluronic acid capsule or M protein, but not cysteine protease, significantly attenuated local soft-tissue necrosis, systemic bacterial dissemination, and mortality.

\section{Methods}

\section{Bacterial strains and plasmids}

GAS strain 950771 is a moderately encapsulated M3 clinical isolate from a child with necrotizing fasciitis and sepsis. Features of this strain and isogenic mutants derived from it are shown in Table I. GAS were grown in Todd-Hewitt broth supplemented with yeast extract to $0.5 \%$ weight/volume (THY). To derive bacterial growth curves, GAS were inoculated in $10 \mathrm{ml}$ THY to an $\mathrm{A}_{600 \mathrm{~nm}}$ of 0.05 and incubated at $37^{\circ} \mathrm{C}$, and the $\mathrm{A}_{600 \mathrm{~nm}}$ was measured over time. GAS were grown on either commercially available trypticase-soy agar medium supplemented with $5 \% \mathrm{vol} / \mathrm{vol}$ sheep blood (TSA-blood; Becton Dickinson Microbiological Systems, Cockeysville, MD) or THY agar supplemented with $5 \% \mathrm{vol} / \mathrm{vol}$ sheep blood (PML Microbiologicals,
Richmond, British Columbia, Canada) (THY-blood). When required, THY-blood medium was supplemented with either kanamycin $500 \mu \mathrm{g} / \mathrm{ml}$ or erythromycin $1.0 \mu \mathrm{g} / \mathrm{ml}$. Escherichia coli were grown in Luria-Bertani (LB) broth and grown on LB agar or brain-heartinfusion agar supplemented as required with ampicillin $50 \mu \mathrm{g} / \mathrm{ml}$, kanamycin $50 \mu \mathrm{g} / \mathrm{ml}$, or erythromycin $250 \mu \mathrm{g} / \mathrm{ml}$. Plasmids were propagated in, and purified from, E. coli strain DH5 $\alpha$ (New England Biolabs, Beverly, MA). Plasmid pWKS30 is a low-copy number cloning vector containing an ampicillin-resistance determinant (25). Plasmid pJRS233 is a temperature-sensitive E. coli-gram-positive shuttle vector containing an erythromycin-resistance determinant (26).

\section{DNA manipulation}

Restriction endonuclease digests, DNA ligations, transformation of chemically competent E. coli, agarose gel electrophoresis, and Southern hybridization were performed according to standard techniques (27). Restriction enzymes and DNA ligase were purchased from Boehringer Mannheim (Indianapolis, IN). Plasmid purification was performed with Wizard mini- or maxi-preps according to the manufacturer's protocol (Promega Corp., Madison, WI). GAS chromosomal DNA was purified according to the method of O'Connor and Cleary (28). DNA probes for Southern hybridization analysis were conjugated to horseradish peroxidase, and hybridization was detected with a chemiluminescent substrate according to the manufacturer's instructions (ECL kit; Amersham Life Science, Arlington Heights, IL).

Derivation of speB, has $A$, and emm3 gene replacement mutants by allelic exchange in GAS strain 950771

Derivation of allelic exchange constructs in pJRS233. To derive strains from GAS strain 950771 with mutations in the speB, has A, or emm3 gene we constructed a series of plasmids containing the target gene with either an $\Omega \mathrm{Km}-2$ interposon (29) insertion (speB, has $A$ ) or an internal deletion (emm3). To derive the speB interposon construct pJspeB $\Omega$, we used PCR and the primer pairs 100/103 and 101/102 (Table II) to amplify from 950771 chromosomal DNA a 343-bp 5' portion and a 371-bp $3^{\prime}$ portion of speB, respectively. We cloned the two PCR products initially into pWKS30 and subsequently into pJRS233 to form the plasmid pJspeB $\Delta$ using a terminal XbaI site specified in primer 100, a terminal SalI site specified in primer 101, and a common BglII site specified in primers 102 and 103. We then cloned BamHI-digested $\Omega \mathrm{Km}-2$ into the internal BglII site in $\mathrm{pJspeB} \Delta$. The resulting construct $\mathrm{pJ} \mathrm{spe} B \Omega$ contained an insert comprising a 343-bp fragment from the $5^{\prime}$ speB terminus linked by the $\sim 2.0 \mathrm{~kb} \Omega \mathrm{Km}-2$ element to a 371-bp fragment from the $3^{\prime}$ speB terminus.

To derive the has $A$ interposon construct pJhas $\mathrm{A} \Omega$, we used PCR and the primers 8 and 79 (Table II) to amplify from 950771 chromosomal DNA a 1052-bp fragment that extended from position -89 upstream of the has $A$ initiation codon to position 963 within has $A$. We

Table I. Bacterial Strains Used in This Study

\begin{tabular}{|c|c|c|c|}
\hline Strain & Relevant genotype & Phenotype & Source \\
\hline \multicolumn{4}{|l|}{ E. coli } \\
\hline DH5 $\alpha$ & & & New England Biolabs \\
\hline \multicolumn{4}{|c|}{ S. pyogenes } \\
\hline $87-282$ & emm18 $8^{+}$as $A B C^{+}$ & M18, heavily encapsulated & 13 \\
\hline 950771 & 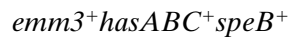 & M3, moderately encapsulated, expresses cysteine protease & This study \\
\hline 188 & has $A:: \Omega \mathrm{Km}-2$ & Acapsular mutant derived from 950771 & This study \\
\hline 326 & has $A:: \Omega \mathrm{Km}-2$ & Acapsular mutant derived from 950771 & This study \\
\hline 241 & speB:: $\Omega \mathrm{Km}-2$ & Cysteine protease-deficient mutant derived from 950771 & This study \\
\hline 296 & $\Delta e m m 3$ & M protein-deficient mutant derived from 950771 & This study \\
\hline 355 & $\Delta e m m 3$ & M protein-deficient mutant derived from 950771 & This study \\
\hline
\end{tabular}




\begin{tabular}{|c|c|c|c|c|}
\hline Name & Sequence & Description* & & $\begin{array}{l}5 \text { ' terminal restriction } \\
\text { endonuclease site }\end{array}$ \\
\hline 8 & cccccctgcagtaaggcaacgatgggattag & has A 963-944 & $\mathrm{R}$ & PstI \\
\hline 79 & ctctatgtctagttgacattacc & has $A-89-(-67)$ & $\mathrm{F}$ & None \\
\hline 100 & cccctctagatcagcagctatcaagcagg & speB $145-164$ & $\mathrm{~F}$ & $\mathrm{XbaI}$ \\
\hline 101 & ccccgtcgaccgagagctacctgcagaacc & speB $860-841$ & $\mathrm{R}$ & SalI \\
\hline 102 & ccccagatcttaacccttacaacctattgac & speB 489-509 & $\mathrm{F}$ & BglII \\
\hline 103 & ccccagatctccttggttgtaatgaatgcc & speB $488-469$ & $\mathrm{R}$ & BglII \\
\hline 104 & gggaattcctatt (g/c)gcttagaaattaa & emm3 27-46 & $\mathrm{F}$ & EcoRI \\
\hline 105 & gcaagttcttcagcttgttt & emm3 1367-1348 & $\mathrm{R}$ & None \\
\hline 106 & ccccagatctgccactttacctaaaac & emm3 371-355 & $\mathrm{R}$ & BglII \\
\hline 107 & ccccagatctgccgtaagggtcttcgccg & етm 3 1139-1157 & $\mathrm{F}$ & $\mathrm{BglII}$ \\
\hline
\end{tabular}

* Numbers indicate location of the oligonucleotide primer with respect to a translational start site at position 1. F, Forward; $R$, reverse. Sequence accession numbers are: hasA, L21187; speB, M86905; and emm3, U40231. Primer 79 was based on an unpublished sequence (Ashbaugh, C.D., S.A. Albertí, and M.R. Wessels, manuscript in preparation).

cloned the PCR product into the plasmid pJRS233 to form the plasmid pJhasA $\Delta$ using a terminal PstI site specified within primer 8 and a HincII site present internally in the PCR product. We then cloned the BamHI-digested $\Omega \mathrm{Km}-2$ element into an internal BglII site in has $A$. The resulting construct pJhasA $\Omega$ contained an insert comprising a 529-bp fragment from the $5^{\prime}$ has $A$ terminus linked by the $\sim 2.0$ $\mathrm{kb} \Omega \mathrm{Km}-2$ element to a 523-bp fragment from the $3^{\prime}$ has $A$ terminus.

To derive an emm 3 deletion construct, we used PCR and the primer pairs 104/106 and 105/107 (Table II) to amplify from 950771 chromosomal DNA a 344-bp 5' portion and a 228-bp 3' portion of emm3, respectively. We then cloned the two PCR products initially into pWKS30 to form the construct pWemm3s using a terminal EcoRI site specified in primer 104, an internal HindIII site specified in the 105/107 PCR product, and a common BglII site specified in primers 106 and 107. We cloned the insert from pWemm $3 \Delta$ into pJRS233 using XbaI and HindIII sites in the pJRS233 polylinker to derive the construct pJemm $3 \Delta$. Plasmid pJemm $3 \Delta$ contained a 572-bp insert comprising a 344-bp fragment from the $5^{\prime}$ emm 3 terminus linked by a BglII site to a 228-bp fragment from the $3^{\prime}$ emm 3 terminus. In linking the $5^{\prime}$ and $3^{\prime}$ fragments, $767 \mathrm{bp}$ of internal emm 3 sequence were deleted.

Gene replacement mutagenesis by allelic exchange in GAS strain 950771. We used a three-step process to introduce the mutant gene present in the pJRS233 constructs into the chromosome of GAS strain 950771 by allelic exchange. The vector pJRS233 contains an erm gene encoding erythromycin resistance and a temperature-sensitive gram-positive replicon that is active at $30^{\circ} \mathrm{C}$ but not at $37^{\circ} \mathrm{C}(26)$. Initially, the constructs were electroporated into GAS strain 950771, and transformants containing free plasmid were selected by their ability to grow at $30^{\circ} \mathrm{C}$ on THY-blood agar media supplemented with erythromycin. In the second step, we selected for strains in which the plasmid had integrated into the 950771 chromosome via a single recombination event over the homologous plasmid insert and chromosome sequence by their ability to grow at $37^{\circ} \mathrm{C}$ on THY-blood agar medium containing erythromycin. In the third step, GAS strains containing plasmid integrated within the chromosome (integrants) were serially passed in broth culture in the absence of antibiotics at $30^{\circ} \mathrm{C}$. Plasmid excision from the chromosome via a second recombination event over the duplicated target gene sequence either completed the allelic exchange or reconstituted the wild-type genotype. Subsequent loss of the plasmid in the absence of antibiotic selection pressure resulted in an erythromycin-sensitive phenotype. We screened erythromycin-sensitive colonies for gene replacement by phenotype (speB, has $A$ ) or by analysis of the target gene PCR amplicon (emm3).

To confirm the mutant genotype, we used Southern hybridization analysis of chromosomal DNA probed with the target gene. Southern hybridization with speB to probe EcoRV/BglII-digested chromosomal DNA from 950771 demonstrated a single 5.4-kb band (Fig. $1 \mathrm{~A}$, lane 1). In the cysteine protease-deficient mutant strain 241 , the same probe hybridized to $4.0-$ and 3.0-kb bands (Fig. $1 \mathrm{~A}$, lane 2). Because the $\Omega \mathrm{Km}-2$ element contained internal EcoRV sites, insertion of the interposon introduced these sites into the 241 chromosome, resulting in two EcoRV/BglII fragments hybridizing to the speB probe. The combined size of the two fragments is 7.0 or $1.6 \mathrm{~kb}$ larger than the wild-type fragment, consistent with insertion of the $\Omega \mathrm{Km}-2$ element in the 241 spe $B$ gene. In addition, because digestion of $\mathrm{pJspe} B \Omega$ with EcoRV/BglII results in a 7.0-kb fragment, the Southern results indicated that the speB mutant did not retain the plasmid used in its derivation.

Southern hybridization using has $A$ to probe EcoRI/BamHIdigested chromosomal DNA from 950771 and the acapsular mutant 188 demonstrated an $8.5-\mathrm{kb}$ BamHI/EcoRI fragment in the wild-type strain (Fig. $1 B$, lane 1 ) and a 10.5-kb BamHI/EcoRI fragment in the acapsular mutant (Fig. $1 \mathrm{~B}$, lane 2) consistent with insertion of the $2.0-\mathrm{kb} \Omega \mathrm{Km}-2$ interposon. The same probe also hybridized to 5.0- and $11.5-\mathrm{kb}$ BglII fragments in the wild-type strain but to a single $19-\mathrm{kb}$ BglII fragment in the acapsular strain due to loss of the BglII site in has $A$ after insertion of the $\Omega \mathrm{Km}-2$ element (data not shown). These results confirmed insertion of $\Omega \mathrm{Km}-2$ within has $A$ in the acapsular mutant 188. Because BamHI/EcoRI digestion of pJhas $\mathrm{A} \Omega$ generates fragments of 6.4 and $2.2 \mathrm{~kb}$, these results also demonstrate that the acapsular mutant 188 did not retain the plasmid used in its derivation. We used a similar approach to independently derive the acapsular mutant 326 and confirm gene replacement.

Southern hybridization using emm 3 to probe EcoRV/BglIIdigested chromosomal DNA from 950771 demonstrated fragments of 1.8 and $1.6 \mathrm{~kb}$ (Fig. $1 C$, lane 1 ). In the emm3 deletion mutant, strain 296, the same probe hybridized to 1.2 - and 1.5 -kb fragments (Fig. $1 C$, lane 2). The reduction in fragment size from 1.8 to $1.2 \mathrm{~kb}$ and from 1.6 to $1.5 \mathrm{~kb}$ confirmed the $767-\mathrm{bp}$ internal deletion in the $296 \mathrm{emm} 3$ gene. Because EcoRV/BglII digestion of pJemm $3 \Delta$ generates a 6.4-kb fragment, these results also indicated that 296 did not retain the plasmid used in its derivation. We used a similar approach and analysis to derive the emm 3 deletion mutant 355 and to confirm allelic exchange, respectively.

\section{Transformation of GAS}

Electrocompetent GAS were prepared and electroporation was performed as described by Caparon and Scott (30). 


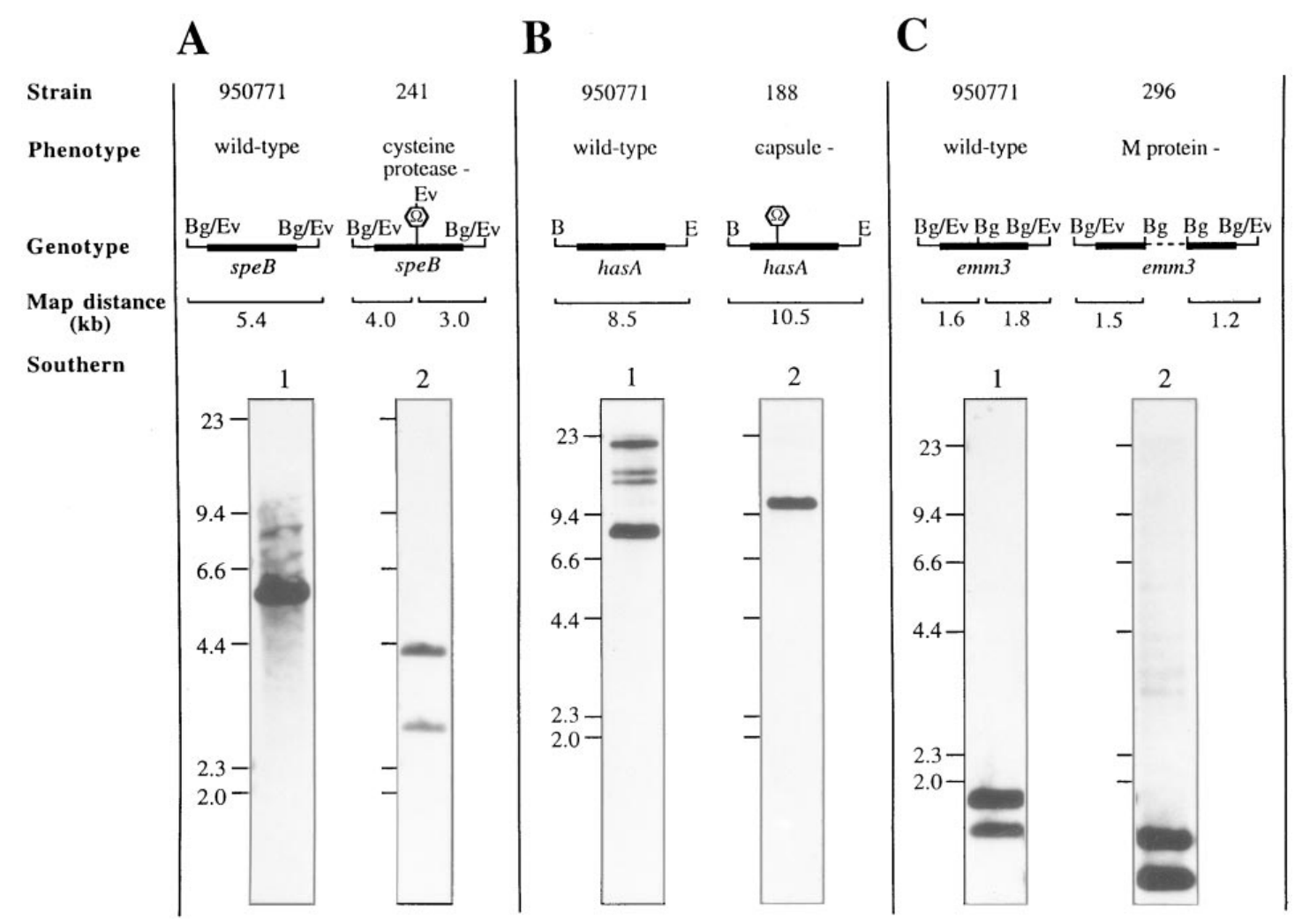

Figure 1. Schematic representation of the GAS chromosome in the invasive clinical isolate 950771 and the isogenic speB mutant 241 ( $A$ ), has $A$ mutant $188(B)$, and emm3 mutant $296(C)$. DNA fragment size in the schematic is not to scale and flanking sequence (horizontal lines) may extend up to $7 \mathrm{~kb}$ beyond the target gene (shaded). Sites of the $2.0-\mathrm{kb} \Omega \mathrm{Km}-2$ interposon insertion are indicated $(\Omega)$. The dashed line in $296 \mathrm{emm} 3$ indicates a 767-bp DNA deletion. B, BamHI; Bg, BglII, $E v$, EcoRV; $E v / B g$, either EcoRV or BglII, exact site not established. Southern hybridization of restriction endonuclease-digested chromosomal DNA from the GAS wild-type and isogenic mutant strains is shown. Migration distances of molecular size standards are indicated. (A) BglII/EcoRV-digested chromosomal DNA from strain 950771 (lane 1) or the speB interposon mutant 241 (lane 2) probed with speB. (B) BamHI/EcoRI-digested chromosomal DNA from strain 950771 (lane 1) or the has $A$ interposon mutant 188 (lane 2) probed with has A. (C) BglII/EcoRV-digested chromosomal DNA from strain 950771 (lane 1) or the emm3 deletion mutant 296 (lane 2) probed with emm3.

\section{$P C R$}

All PCR reactions were performed according to standard techniques (27). Oligonucleotide primers were purchased from the Midland Reagent Company (Midland, TX) and are shown in Table II. GAS chromosomal DNA template was prepared as described previously (28). Taq DNA polymerase and dNTPs were purchased from Boehringer Mannheim (Indianapolis, IN).

\section{Determination of cysteine protease production}

GAS expression of extracellular cysteine protease was determined by a plate assay slightly modified from the original description by Hynes and Tagg (31). $8.75 \mathrm{~g}$ Columbia broth (Difco Laboratories, Detroit, $\mathrm{MI})$ and $0.5 \mathrm{~g}$ agar (Difco) were dissolved in $250 \mathrm{ml}$ of deionized water. In a separate container $7.5 \mathrm{~g}$ of skim milk (Difco) was dissolved in $250 \mathrm{ml}$ of deionized water. The two solutions were autoclaved and combined after cooling to $50^{\circ} \mathrm{C}$ to give a final medium composed of 0.5 -strength Columbia broth, $3 \% \mathrm{wt} / \mathrm{vol}$ skim milk, and $1 \% \mathrm{wt} / \mathrm{vol}$ agar. GAS were stab-inoculated into petri dishes containing the assay medium. Protease-expressing strains produced a ring of precipitate surrounding the site of inoculation after a $24-\mathrm{h}$ incubation at $37^{\circ} \mathrm{C}$.

\section{Determination of cell-associated hyaluronic acid}

GAS capsule production was quantified by measurement of cell-associated hyaluronic acid using the carbocyanine dye 1-ethyl-2-[3-
(1- ethyl-naphtho[1,2d]thiazolin-2-ylidene)-2-methyl-propenyl]naphtho[1,2d]-thiazolium bromide (Stains All; Sigma Chemical Co., St. Louis, MO) as previously described (16). All measurements were made in duplicate.

\section{Determination of $M$ protein expression}

Acid extracts of GAS surface M protein were prepared from 100-ml broth cultures as described by Lancefield (32). Equivalent amounts of the extracted proteins were separated by SDS-PAGE (27) and the separated proteins were transferred to a nitrocellulose membrane for Western immunoblotting (27) using rabbit antiserum raised against GAS M3 strain 764 and alkaline phosphatase-conjugated anti-rabbit $\mathrm{IgG}$ as the secondary antibody (Pierce, Rockford, IL).

\section{Murine invasive soft-tissue infection}

Female 6-8-wk-old CD1 mice (Charles River Laboratories, Connaught, MA) were inoculated with GAS as previously described (16). Briefly, mice were anesthetized and the hair was removed from the right flank with Nair (Carter Products, New York). Approximately $10^{8} \mathrm{cfu}$ of GAS from an early log-phase broth culture were suspended in $50 \mu \mathrm{l}$ of sterile pyrogen-free water and inoculated just under the surface of the skin with a 27 -gauge needle. The animals were observed daily for 10-14 d. Serial tail-vein phlebotomy was performed typically on days 1,4 , and $7.50-100 \mu l$ of blood was inoculated on 
blood-agar medium and incubated at $37^{\circ} \mathrm{C}$ for $24 \mathrm{~h}$, at which point the plates were examined for the presence of $\beta$-hemolytic colonies. Animals surviving to the end of the experiment (either day 10 or day 14), or animals that appeared moribund at any time, were killed and the spleen was removed by aseptic technique. The spleen was homogenized with a scalpel blade in $1.0 \mathrm{ml}$ of THY broth, and $100 \mu \mathrm{l}$ of the splenic homogenate was cultured on TSA-blood agar. In some experiments, animals were killed at various time points during infection, and tissue sections from the site of inoculation were prepared for histopathologic examination.

\section{Tissue histopathology}

A tissue block of skin and subcutaneous tissue from the site of inoculation was dissected from representative animals. Tissues were fixed in $10 \mathrm{vol}$ of $10 \%$ neutral buffered formalin, imbedded in paraffin, and sectioned at 4-6 $\mu \mathrm{m}$. Duplicate tissue sections were stained with hematoxylin and eosin and a tissue gram stain (Brown \& Hopps) by standard techniques (33).

\section{Immunofluorescence microscopy}

Tissue sections immobilized in paraffin were fixed to glass slides by baking at $65^{\circ} \mathrm{C}$ for $1 \mathrm{~h}$. The paraffin was removed by immersion of the fixed section in xylene for $5 \mathrm{~min}$, and the slide was washed in $95 \%$ ethanol for $90 \mathrm{~s}$. The ethanol washes were repeated three times, and the sections were placed in deionized water. To prevent nonspecific antibody binding, the sections then were incubated with blocking solution $(0.5 \%$ wt/vol BSA; Sigma Chemical Co., St. Louis, MO) in PBS, pH 7.0 for $1 \mathrm{~h}$. Subsequently, the blocking solution was removed, and the sections were overlaid at room temperature for $1 \mathrm{~h}$ with either rabbit anti-group A carbohydrate $\operatorname{IgG}(7.5 \mu \mathrm{g} / \mathrm{ml}$ in $0.5 \%$ BSA/PBS, kindly provided by Joseph Crabb, Immucell Corp., Portland, ME) or a control antibody, rabbit anti-Pseudomonas aeruginosa lipopolysaccharide IgG $(7.5 \mu \mathrm{g} / \mathrm{ml}$ in $0.5 \%$ BSA/PBS, kindly provided by Michael Preston, Harvard Medical School). The sections then were washed with PBS to remove unbound antibody and overlaid at room temperature with goat anti-rabbit IgG conjugated to the fluorescent dye Texas red $(7.5 \mu \mathrm{g} / \mathrm{ml}$ in $0.5 \%$ BSA/PBS; Accurate Chemical and Scientific Corp., Westbury, NY). After $1 \mathrm{~h}$, the sections were washed twice with PBS and examined with a Nikon Diaphot mi- croscope (Nikon Inc., Melville, NY) equipped with a XF64 filter (excitation wavelength $560-580 \mathrm{~nm}$, emission wavelength $610-675 \mathrm{~nm}$; Omega Optical Inc., Brattleboro, VT).

\section{Statistical analysis}

Statistical calculations were performed with S-Plus Version 3.2 software (Statistical Sciences Inc., Seattle, WA). Analysis of time to positive blood culture in mice inoculated subcutaneously with GAS was performed with maximum likelihood with a Weibull model for interval-censored responses (34). Analysis of survival data in mice inoculated subcutaneously with GAS was performed either with log-rank tests or Kaplan-Meier survival function estimates (34). In the 10 experiments in which animals were challenged with the wild-type strain there were modest differences in the inoculum (range $1.0 \times 10^{7}$ to $7.5 \times 10^{8}$; mean $1.6 \times 10^{8}$ ). For these experiments both time to positive culture and time to death analyses were performed using proportional hazards regression allowing for either continuous or categorical inoculum effects. No significant dose effect was found (minimum $P$ over all tests of dose effect was 0.23 ) and inferences on strain effects were not affected by controlling for dose. Consequently, the 10 experiments involving animals challenged with the wild-type strain were combined. In three animals challenged with mutant strain 188 and in two animals challenged with mutant strain 296, wild-type organisms were the sole isolates recovered from the blood or spleen. For the purpose of statistical analysis, these animals were considered to be bacteremic with the challenge (mutant) strain.

\section{Results}

Characterization of murine invasive soft-tissue infection caused by wild-type GAS strain 950771

To investigate the pathogenesis of invasive GAS disease, we characterized the host response to bacterial challenge with the M3 GAS strain 950771 in a murine model of human invasive soft-tissue infection. Adult mice were challenged subcutaneously with GAS and observed for changes in the appearance of the skin overlying the site of inoculation in the course of a 10-

Table III. GAS Invasive Soft-Tissue Infection in Mice

\begin{tabular}{|c|c|c|c|c|c|c|c|c|}
\hline \multirow[b]{2}{*}{ Strain } & \multirow[b]{2}{*}{ Phenotype } & \multirow[b]{2}{*}{ Animals } & \multirow[b]{2}{*}{ Experiments } & \multirow[b]{2}{*}{ Inoculum mean (range) } & \multicolumn{2}{|c|}{ Appearance of skin lesion* } & \multirow{2}{*}{$\begin{array}{l}\text { Blood or spleen } \\
\text { culture positive } \\
\text { (\%) }\end{array}$} & \multirow[b]{2}{*}{$\begin{array}{l}\text { Mortality } \\
(\%)\end{array}$} \\
\hline & & & & & Abscess & $\begin{array}{c}\text { Spreading } \\
\text { necrosis }\end{array}$ & & \\
\hline & & $n$ & $n$ & & & & & \\
\hline 950771 & Wild-type & 64 & 10 & $\begin{array}{c}1.6 \times 10^{8} \\
\left(1.0 \times 10^{7} \text { to } 7.5 \times 10^{8}\right)\end{array}$ & 9 & 52 & $45 / 64(70)$ & $45 / 64(70)$ \\
\hline 241 & $\begin{array}{l}\text { Cysteine } \\
\text { protease - }\end{array}$ & 12 & 2 & $\begin{array}{c}1.1 \times 10^{8} \\
\left(3.3 \times 10^{7} \text { to } 1.9 \times 10^{8}\right)\end{array}$ & 0 & 10 & $11 / 12^{\S}(92)$ & $11 / 12^{\S}(91)$ \\
\hline 188 & Capsule - & 12 & 2 & $\begin{array}{c}8.7 \times 10^{7} \\
\left(5.4 \times 10^{7} \text { to } 1.2 \times 10^{8}\right)\end{array}$ & 12 & 0 & $3 / 12^{\|\| \|}(25)$ & $0 / 12^{\mathbb{I l}}(0)$ \\
\hline 326 & Capsule - & 10 & 1 & $1.2 \times 10^{8}$ & 10 & 0 & $0 / 10^{\text {If }}(0)$ & $0 / 10^{\text {I }}(0)$ \\
\hline 296 & M protein - & 12 & 2 & $\begin{array}{c}6.3 \times 10^{7} \\
\left(4.1 \times 10^{7} \text { to } 8.5 \times 10^{7}\right)\end{array}$ & 12 & 0 & $2 / 12 * * \pi(17)$ & $0 / 12^{\mathbb{I I}}(0)$ \\
\hline 355 & M protein - & 10 & 1 & $7.2 \times 10^{7}$ & 10 & 0 & $0 / 10^{\text {II }}(0)$ & $0 / 10^{\text {II }}(0)$ \\
\hline
\end{tabular}

*Description of the predominant characteristic of the lesion. In experiments involving the strains 950771 and 241 the sum of the lesions recorded does not equal the number of the animals studied because some animals died before developing either an abscess or skin necrosis. ${ }^{\star}$ Recorded as positive if any blood or spleen culture grew $\beta$-hemolytic colonies. ${ }^{\circledR} P$ value $\geq 0.14$ compared with the wild-type strain. "Wild-type organisms recovered from the spleen of healthy appearing animals killed at day $10 .{ }^{\top} P$ value $\leq 0.007$ compared with the wild-type strain. **Wild-type organisms recovered from the blood of healthy appearing animals on day 4 . Subsequent blood cultures on day 7 and spleen cultures on day 10 were negative. 

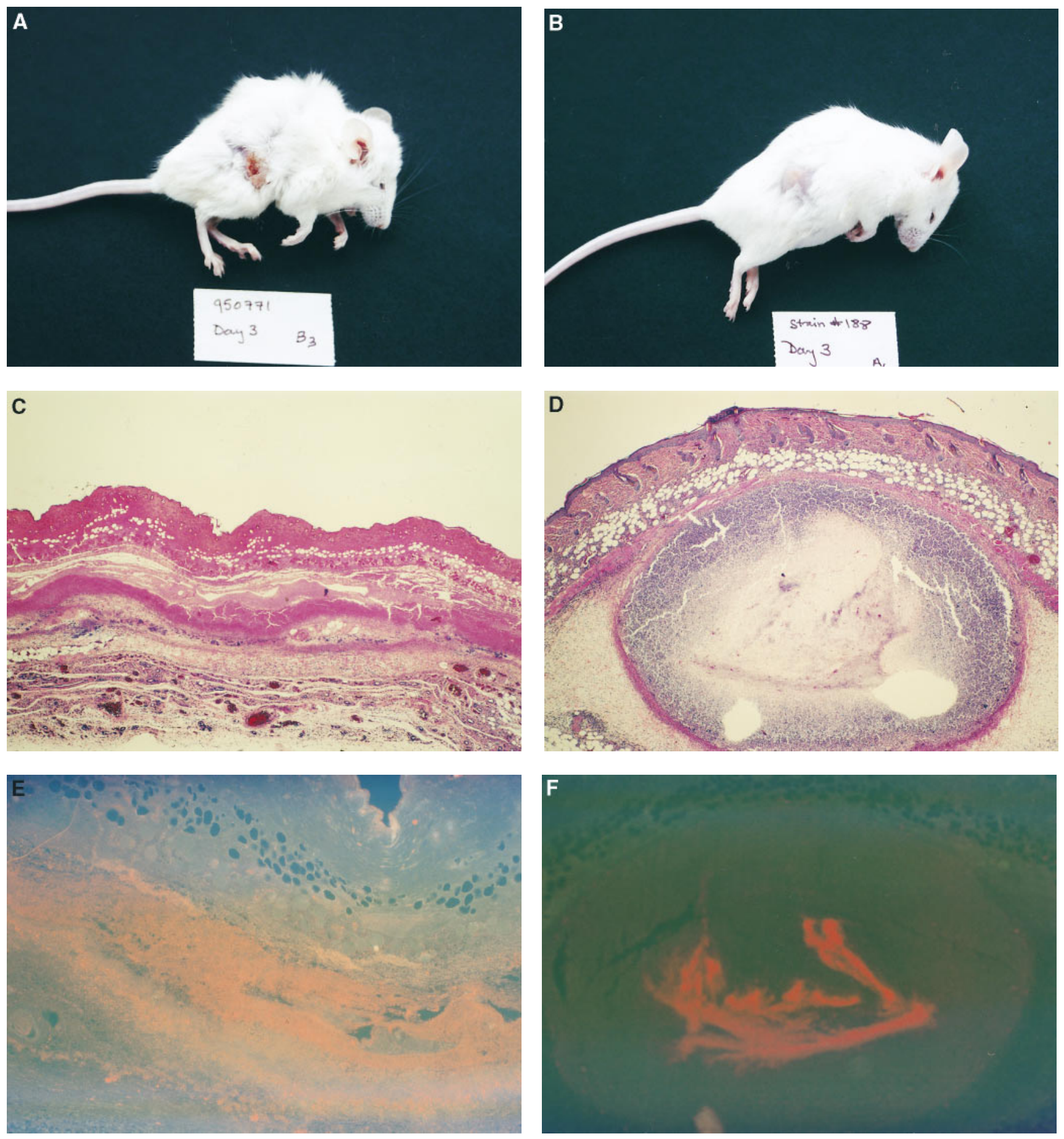

Figure 2. Gross pathology and histopathology of the local skin lesion in mice after subcutaneous injection with GAS. (A) Skin necrosis on day 3 overlying the site of inoculation in a mouse infected with wild-type strain 950771. (B) Abscess at day 3 at the site of inoculation in a mouse infected with the acapsular strain 188. (C) Hematoxylin and eosin stain of a day 3 soft-tissue lesion from a mouse inoculated with wild-type strain $950771(\times 20)$. The subcutaneous tissue is intensely inflamed, vessels within the area of inflammation are thrombosed, and the overlying dermis and epidermis are infarcted and necrotic. $(D)$ Hematoxylin and eosin stain of a day 3 soft-tissue lesion from a mouse inoculated with acapsular strain $188(\times 20)$. In contrast to the necrotic lesion seen in animals challenged with the wild-type strain, there is a well-formed subcutaneous abscess without associated vessel infarction or overlying skin necrosis. (E) Immunofluorescence of a day 3 soft-tissue infection from a mouse inoculated with the wild-type strain $950771(\times 20)$. GAS (red) are widely disseminated in the subcutaneous tissue. $(F)$ Immunofluorescence of a day 3 soft-tissue infection from a mouse inoculated with the M protein-deficient mutant strain 296. GAS (red) remain confined within a subcutaneous abscess $(\times 10)$. 
or 14-d experiment (Table III). The majority of animals (52 of 64) developed an area of spreading tissue necrosis extending from the site of inoculation (Fig. $2 A$ ). The skin lesions evolved in a characteristic manner. A small ( $\leq 5.0 \mathrm{~mm}$ diameter) area of swelling and erythema formed on day 1 or 2 . Beginning on day 3 and continuing thereafter, the central portion of the lesion became necrotic, and the area of necrosis extended circumferentially (5.0-15.0 mm diameter). Among the 12 animals that did not develop a spreading necrotic skin lesion, 9 developed focal swelling and erythema consistent with an abscess, and 3 died on day 1 or 2 before either skin necrosis or an abscess developed.

To characterize the local lesion, we killed animals at day 3 or 4 and prepared sections of skin and underlying soft-tissue from the site of inoculation for histopathologic examination. Hematoxylin and eosin staining of the lesion demonstrated extensive polymorphonuclear infiltration in the subcutaneous tissue. Arterioles and venules within the area of acute inflammation were thrombosed, and the cellular detail of the dermis and epidermis was effaced by extensive infarction and coagulation necrosis (Fig. 2 C). Tissue gram stain and immunofluorescence microscopy revealed GAS throughout the inflamed subcutaneous tissue (Fig. 2 E).

To determine the ability of GAS strain 950771 to disseminate from a local skin lesion and cause fatal infection after subcutaneous inoculation in mice, we followed animals for the development of a positive blood or spleen culture and recorded their survival (Table III). A total of 45 (70\%) of 64 animals challenged with 950771 developed bacteremia and died. Analysis of the time to first positive blood culture indicated that $\sim 50 \%$ of animals developed bacteremia by day 3 and that the development of bacteremia after day 7 was unusual (Fig. 3). Analysis of survival indicated that bacteremia preceded fatal infection by $\sim 36-48 \mathrm{~h}, \sim 50 \%$ of the animals died by day 5 , and the majority of deaths occurred between days 3 and 8 (Fig. 4).
Role of the cysteine protease, hyaluronic acid capsule, and $M$ protein in murine invasive soft-tissue infection

Derivation of the cysteine protease-deficient mutant 241 by allelic exchange in GAS strain 950771. To derive a cysteine protease-deficient mutant from the mouse-virulent GAS strain 950771, we used allelic exchange mutagenesis to insert the $\Omega \mathrm{Km}$-2 element (29) in the speB gene encoding the cysteine protease (35). A schematic representation of the wild-type and mutant chromosome is shown in Fig. 1. To confirm that the mutant genotype resulted in a cysteine protease-deficient phenotype, we tested the ability of the parent and mutant strain 241 to generate an opaque precipitate surrounding the site of bacterial inoculation in Columbia skim-milk medium (31). In contrast to the wild-type strain, the cysteine protease-deficient mutant showed no evidence of proteolysis. Growth curves of the wild-type strain 950771 and the cysteine protease mutant 241 were superimposable.

The cysteine protease mutant 241 is fully virulent in murine invasive soft-tissue infection. To investigate the role of the cysteine protease in the development of GAS invasive infection, we tested the ability of the cysteine protease-deficient mutant 241 to cause tissue necrosis, bacteremia, and fatal infection in the murine model (Table III). Animals challenged with strain 241 developed necrotic skin and soft-tissue lesions similar in time course, gross appearance, and histopathology to those in animals challenged with the wild-type strain. Intense acute inflammation in the subcutaneous tissues was associated with vessel thrombosis and infarction of the overlying skin. Tissue gram-stain and immunofluorescence microscopy revealed GAS disseminated in the subcutaneous tissue. There were no significant differences between animals challenged with either the parent or the mutant strain with respect to the time to first positive blood culture (Fig. 3) or survival (Fig. 4). To confirm that the virulence of the cysteine protease-deficient mutant was not due to a population of bacteria that had reverted to the wild-type phenotype and recovered the ability to express the

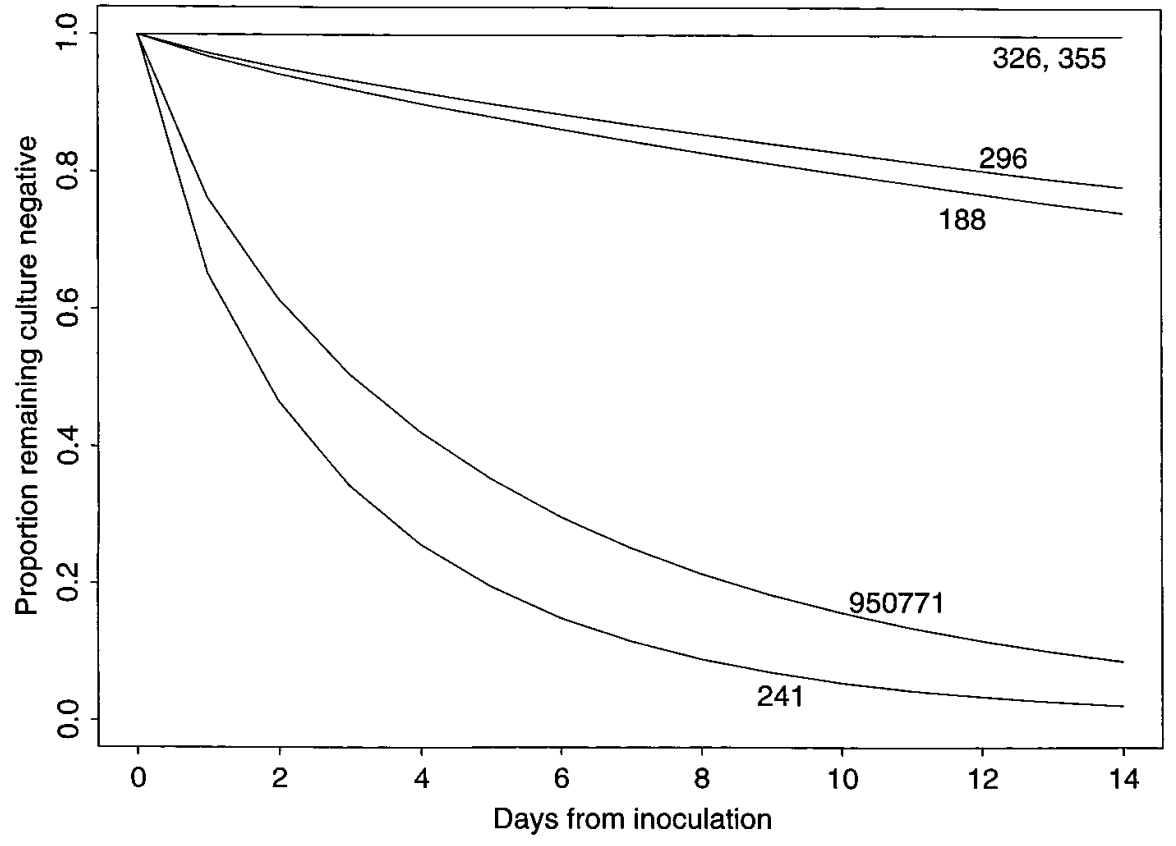

Figure 3. Analysis of time to first positive blood culture in mice inoculated subcutaneously with GAS. In three animals challenged with mutant strain 188 and in two animals challenged with mutant strain 296 , wild-type organisms were the sole isolates recovered from the blood or spleen. For the purpose of statistical analysis, these animals were considered to be bacteremic with the challenge (mutant) strain. Compared with the wild-type strain 950771 (64 animals), the time to first positive culture was significantly longer for the acapsular mutant strains 188 (12 animals) and 326 (10 animals) $(P<0.001)$ and for the M protein-deficient mutant strains 296 (12 animals) and 355 (10 animals) $(P<0.001)$, but not significantly different for the cysteine protease-deficient strain 241 (12 animals) $(P=0.19)$. 
A

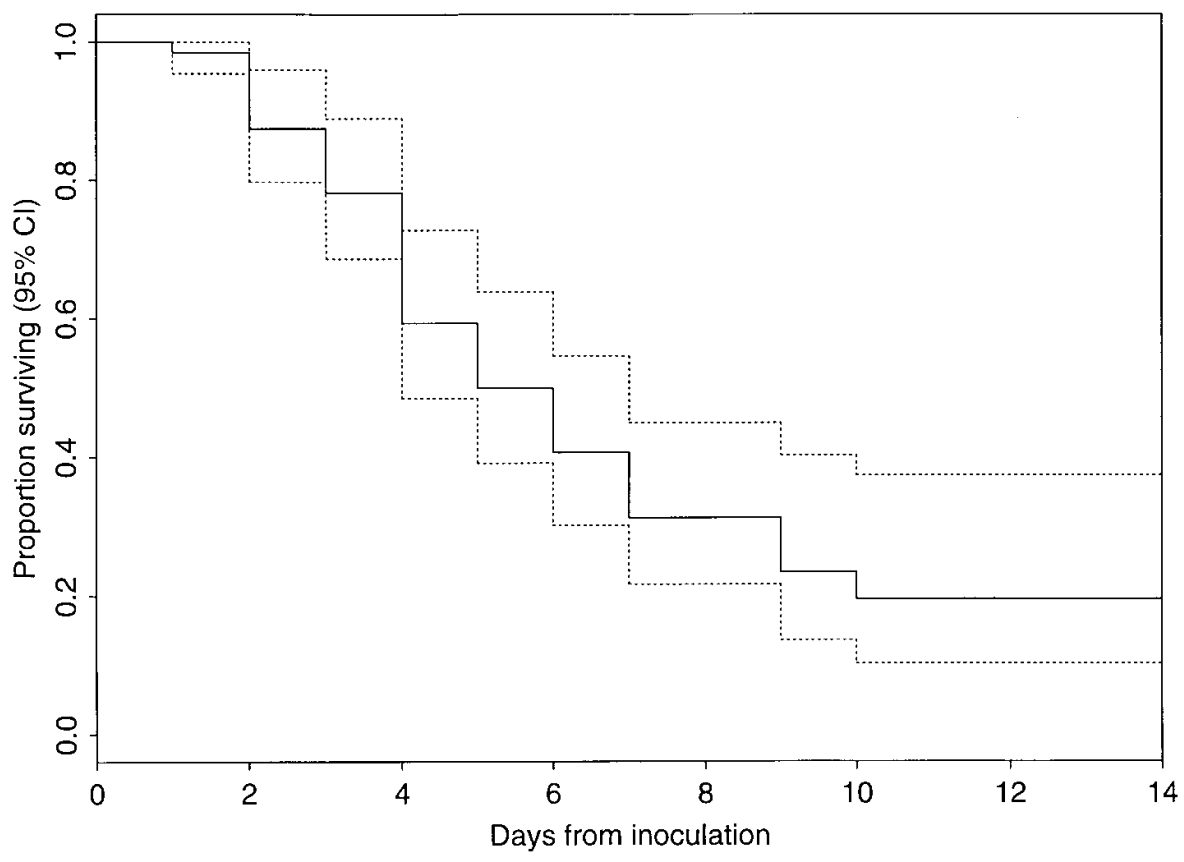

B

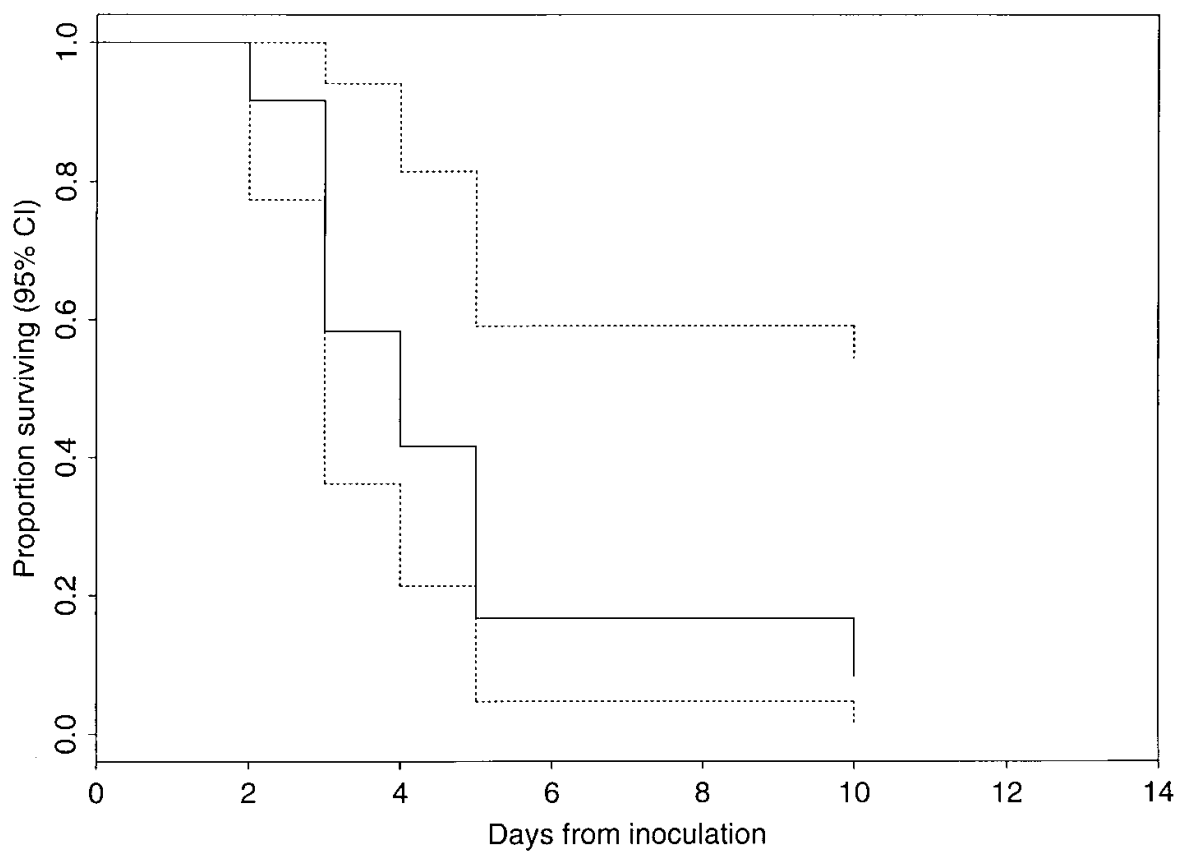

Figure 4. Survival of mice inoculated subcutaneously with either the wild-type strain 950771 (64 animals) or the cysteine protease-deficient strain 241 (12 animals). Solid lines are Kaplan-Meier survival function estimates (34). Dashed lines indicate $95 \%$ confidence intervals. $(A)$ Survival of animals challenged with wild-type strain 950771. (B) Survival of animals challenged with cysteine protease-deficient strain 241. There was no significant difference in survival between the two groups $(P=0.12)$. Because there were no deaths in animals challenged with the acapsular strains 188 and 326 or with the M protein-deficient strains 296 and 355, survival curves for these animals are not shown. protease, GAS isolated from the blood and spleen of animals challenged with strain 241 were assayed for either cysteine protease production (five animals in experiment 1) or kanamycin resistance at $37^{\circ} \mathrm{C}$ on agar medium (six animals in experiment 2). All of the 11 blood or spleen isolates retained the mutant phenotype.

Derivation of the acapsular mutant strains 188 and 326 by allelic exchange in GAS strain 950771. To derive the isogenic acapsular mutant strains 188 and 326 from the mouse virulent GAS strain 950771, we used allelic exchange mutagenesis in two independent experiments to insert the interposon $\Omega \mathrm{Km}-2$
(29) in the has $A$ gene encoding hyaluronic acid synthase (36, 37). A schematic representation of the wild-type and mutant chromosome is shown in Fig. 1. To prove that the has $A$ mutation in strains 188 and 326 inactivated the synthase and abrogated capsule expression, we measured cell-associated capsular polysaccharide. Production of hyaluronic acid in the heavily encapsulated GAS M18 strain 87-282 was $116 \mathrm{fg} / \mathrm{cfu}$. By comparison, the mouse-virulent M3 strain 950771 produced $43 \mathrm{fg} / \mathrm{cfu}$ of hyaluronic acid and the has $A$ mutant strains 188 and 326 produced levels of hyaluronic acid below $10 \mathrm{fg} / \mathrm{cfu}$, the limit of detection in the assay. These results demonstrated 
moderate levels of capsule production in 950771 and the absence of capsule production in mutants 188 and 326. Growth curves of the wild-type strain and the acapsular mutants were superimposable.

Acapsular mutants 188 and 326 are attenuated in murine invasive soft-tissue infection. In contrast to the spreading necrotic lesion that developed in animals challenged with the wild-type strain, animals challenged with the acapsular mutant strains 188 and 326 developed a small $(5.0-10.0 \mathrm{~mm})$ area of focal swelling and erythema (Table III and Fig. $2 B$ ). The lesions reached maximum size on days 3-4, remained stable through day 7, and then regressed such that by day 14 there was little or no swelling or erythema at the site of inoculation. Histopathology of the mature (day 3) local lesion demonstrated a well-formed subcutaneous abscess surrounded by clearly defined fibrin margins (Fig. $2 \mathrm{D}$ ). There was no evidence of vessel thrombosis or significant necrosis outside of the abscess cavity. Tissue gram stain and immunofluorescence microscopy revealed bacteria confined within the abscess and not in the adjacent subcutaneous tissue.

The ability of local host defenses to contain the acapsular mutants in an abscess was associated with the absence of bacteremia or fatal infection (Table III and Fig. 3). None of 12 animals challenged with the acapsular mutant 188 and none of 10 animals challenged with the independently derived acapsular mutant 326 had bacteria isolated from the blood. In three animals challenged with strain 188 , small numbers of bacteria (3 cfu) were cultured from the splenic homogenates of mice that appeared well and were killed at day 10. PCR amplification of the has $A$ gene from the chromosome of the 188 splenic isolates generated an amplicon of similar size to the PCR product using wild-type DNA as a template. None of the 12 animals challenged with strain 188 and none of the 10 animals challenged with strain 326 died.

Derivation of the M protein-deficient mutant strains 296 and 355 by allelic exchange in GAS strain 950771. To derive the isogenic M protein-deficient mutants 296 and 355 from the mouse virulent strain 950771, we used allelic exchange mutagenesis in independent experiments to delete a 767-bp internal segment of the emm3 gene encoding the M3 protein (38). A schematic representation of the wild-type and mutant chromosome is shown in Fig. 1. To demonstrate that the internal deletion in the emm3 gene resulted in the loss of surface $\mathrm{M}$ protein in strains 296 and 355, we prepared M protein extracts from the parent strain 950771 and the emm3 deletion mutants and analyzed the extracts by Western immunoblot using $M$ protein antiserum. There were two prominent bands of $\sim 65$ and $50 \mathrm{kD}$ in the wild-type strain but no immunoreactive bands in either of the M3 deletion mutants (data not shown). These results confirmed loss of cell surface $M$ protein in the emm3 deletion mutants 296 and 355. Growth curves of the wild-type strain and the M protein-deficient mutants were superimposable.

The M protein-deficient mutants 296 and 355 are attenuated in murine invasive soft-tissue infection. Animals challenged with the M protein-deficient mutants 296 and 355 developed a small ( $\leq 10.0 \mathrm{~mm}$ diameter) area of swelling and erythema with no necrosis or with a small area of necrosis limited to the apex of the swelling (Table III). The lesions developed over the first 3-4 d, remained unchanged through days 4-7, and then regressed. Histopathology of the skin lesion demonstrated a well-formed subcutaneous abscess. There was no evi- dence of vessel thrombosis or significant tissue necrosis, although in some animals a small area of necrosis was seen overlying the apex of the abscess. Immunofluorescence microscopy revealed bacteria completely confined within the abscess cavity (Fig. 2 F).

As in animals challenged with the acapsular GAS strains, the ability of local host defenses to contain the M protein-deficient mutants within an abscess was associated with the absence of bacteremia or fatal infection (Table III and Fig. 3). 2 of 12 animals challenged with strain 296 and none of 10 animals challenged with strain 355 had positive blood cultures. The two animals that developed bacteremia after challenge with strain 296 did so early in infection, the animals appeared well, and subsequently the bacteremia cleared. PCR amplification of the emm3 gene from the chromosomal DNA of GAS recovered from the blood of the two bacteremic animals generated an amplicon similar in size to the wild-type PCR product. None of the 12 animals challenged with strain 296 and none of the 10 animals challenged with strain 355 died.

\section{Discussion}

To investigate the molecular events leading to invasive GAS disease, we characterized the host response to bacterial challenge in a murine model of human invasive soft-tissue infection. The majority of animals challenged with wild-type GAS M3 strain 950771 developed spreading skin and soft-tissue necrosis, became bacteremic, and subsequently died, all features common to human infection $(5,6)$. Histopathology of the local lesion demonstrated GAS disseminated in the intensely inflamed subcutaneous tissue. Vessels in the area of inflammation were thrombosed, and the surrounding subcutaneous tissue and overlying skin was infarcted. Failure to contain the infection within an abscess and the presence of vessel thrombosis with soft-tissue infarction are characteristic pathologic findings in human necrotizing fasciitis (39). These observations suggest that the mouse model reproduces important features of human disease and that the model will be useful in investigating the pathogenesis of GAS invasive soft-tissue infection.

To determine the role of the cysteine protease, the hyaluronic acid capsule, and $\mathrm{M}$ protein in the pathogenesis of invasive infection, we derived isogenic spe $B$, has $A$, and emm3 gene replacement mutants from the M3 clinical isolate and tested their ability to cause invasive disease in the murine model. Loss of cysteine protease production had no apparent effect on the ability of GAS to cause local tissue injury and invasive infection. Animals challenged with the cysteine protease-deficient strain developed spreading necrotic skin lesions, bacteremia, and fatal infection in similar numbers and at similar rates to animals challenged with the wild-type strain. Histopathology of the local lesion also was similar to the lesions in animals infected with the parent strain, demonstrating spreading local infection in association with acute inflammation, vessel thrombosis, and tissue infarction. Analysis of the organisms isolated from the blood or spleen of infected animals confirmed the mutant phenotype, indicating that bacterial virulence in the model was not due to GAS that had reverted to the wild-type genotype and recovered the ability to produce the protease.

Recently, Lukomski et al. reported that a cysteine protease-deficient M3 strain and to a lesser extent a proteasedeficient M49 strain were less virulent in mice after intraperitoneal challenge than the protease-producing wild-type strains 
from which they were derived (11). The diminished virulence of the M3 strain was associated with more efficient phagocytic clearance of the organism from the peritoneum (12). Although our results do not exclude the possibility that the GAS cysteine protease contributes to the pathogenesis of other types of invasive infection, they indicate that the protease is not required for invasive soft-tissue infection. In addition, these findings suggest that if the cysteine protease inhibits bacterial clearance either by impairing neutrophil recruitment via release of C5a peptidase from the bacterial surface or by limiting phagocytic killing via release of antiphagocytic fragments from surface bound M protein (24), the effect is minimal in the softtissue infection model.

In contrast to the wild-type and cysteine protease-deficient strains, both the acapsular and $\mathrm{M}$ protein-deficient mutants were avirulent in mice after subcutaneous inoculation. Animals challenged with these mutants developed a small area of swelling and erythema at the site of inoculation that typically did not progress to necrosis, although rarely there was a small area of necrosis confined to the apex of the lesion. The histopathologic findings were notable for GAS contained in a wellformed abscess without evidence of vessel thrombosis or infarction of adjacent tissues. Animals challenged with either the acapsular or the $\mathrm{M}$ protein-deficient mutants rarely had bacterial dissemination from the local lesion, and there were no fatal infections.

Several lines of evidence support the conclusion that the attenuated virulence of the acapsular and $\mathbf{M}$ protein-deficient mutants was due to the targeted gene replacement. First, in broth culture, growth rates of the wild-type and mutant strains were similar, which suggests that the diminished virulence of the mutants was not due to impaired growth in vivo. Second, independently derived acapsular and $\mathrm{M}$ protein-deficient mutant strains demonstrated the same attenuated phenotype in the murine model, which would be unlikely if unexpected random mutations were responsible for the decrease in virulence. Third, the cysteine protease mutant, which was derived by the same methods as the acapsular and M protein-deficient mutants, was fully virulent in mice, thus suggesting that in vitro passage did not nonspecifically diminish the virulence of the acapsular or M protein-deficient strains. Finally, polar effects, although likely in the has $A$ mutants, would almost certainly be limited to the two downstream genes in the has operon, has $B C$, and not affect transcription of distal genes beyond the has operon transcriptional terminator $(40,41)$. Polar effects from the emm3 deletion are not expected. Together these observations strongly suggest that the attenuated virulence of the $188 / 326$ and 296/355 mutant pairs was due to the loss of the hyaluronic capsule and $\mathrm{M}$ protein, respectively.

These results indicate that the hyaluronic acid capsule and $\mathrm{M}$ protein profoundly affect the ability of GAS to cause both spreading tissue necrosis and fatal invasive infection. Examination of the local lesion by immunofluorescence microscopy revealed the spread of the GAS wild-type strain throughout the subcutaneous tissue, whereas the acapsular or M proteindeficient mutants remained confined within an abscess cavity. Because both the capsule and $\mathrm{M}$ protein inhibit complementmediated opsonophagocytosis $(13,17,18)$, it is probable that increased susceptibility to phagocytic killing contributes to the inability of either the acapsular or $\mathrm{M}$ protein-deficient mutants to escape local containment by abscess formation.

The critical requirement for the hyaluronic acid capsule in the development of invasive skin infection in mice challenged with the moderately encapsulated M3 strain used in this study is similar to our previous findings using a heavily encapsulated M24 strain (16). Full virulence of the M3 strain suggests that even the moderate amount of capsule produced by this strain enhances virulence, or that GAS may increase capsule expression in response to the in vivo environment. Favoring the possibility that production of capsule increases in vivo is the observation by us and others that the colony morphology of GAS strains may become more mucoid after animal passage.

In the few animals challenged with either the acapsular or $\mathrm{M}$ protein-deficient mutant in which bacteria were recovered from the blood or the spleen, the organisms had the wild-type genotype. Either contamination of the mutant inoculum with the wild-type strain, or reversion of the mutants to the wildtype strain during infection could account for the recovery of wild-type organisms from these animals. We favor the possibility that the mutants reverted to the wild-type strain during the course of infection for several reasons. First, the freezer stock of the mutants was prepared from a single bacterial colony making contamination with other bacteria unlikely. Second, in the case of the has $A$ mutant, the inoculum containing the acapsular strain was grown in the presence of kanamycin before challenge. Wild-type bacteria should not grow under these conditions because they lack the kanamycin resistance determinant used to make the acapsular mutant. Third, again with respect to the acapsular mutant, we never observed mucoid or encapsulated colonies when the inoculum was plated to determine the challenge dose suggesting that wild-type contaminants were not present. Reversion, although infrequent, is likely due to a second cycle of allelic exchange in small numbers of bacteria that were not cured of the plasmid during the initial gene replacement. Because the mutant phenotype was stable in vitro, these findings suggest that during the development of the local infection there are strong selective pressures for the expression of the capsule and $M$ protein, an observation that has been made previously with respect to the capsule, but which is novel to $M$ protein $(15,42,43)$.

In the present investigation, we have characterized a murine model of invasive soft-tissue infection with GAS that reproduces many of the clinical and histopathologic features of human disease. Development of such a model and of techniques for construction of isogenic mutants of GAS deficient in putative virulence factors made it possible to evaluate the contribution of three of these factors to the pathogenesis of invasive infection. Results of these studies demonstrate that expression of both the hyaluronic acid capsule and $\mathrm{M}$ protein are critical for the development of spreading tissue necrosis, secondary bacteremia, and lethal systemic infection. In contrast, expression of the cysteine protease encoded by spe $B$ was not necessary either for spreading local infection or for bacterial invasion. We conclude that the hyaluronic acid capsule and $\mathrm{M}$ protein are essential virulence factors in invasive GAS soft-tissue infection, while the importance of cysteine protease remains to be established.

\section{Acknowledgments}

We thank Sarah Henderson and Ervin Meluleni for expert technical assistance. We thank Edward Kaplan, Sidney Kushner, June R. Scott, and Michael G. Caparon for contributing bacterial strains and plasmids. 
This work was supported by Public Health Service grants AI29952 (M.R. Wessels) and AI01343 (C.D. Ashbaugh) and contract AI75236 from the National Institute of Allergy and Infectious Diseases and by a Child Health Research grant from the Charles $\mathrm{H}$. Hood Foundation (C.D. Ashbaugh).

\section{References}

1. Davies, H.D., A. McGeer, B. Schwartz, K. Green, D. Cann, A.E. Simor, D.E. Low, and The Ontario Group A Streptococcal Study Group. 1996. Invasive group A streptococcal infections in Ontario, Canada. N. Engl. J. Med. 335: $547-554$

2. Cleary, P.P., E.L. Kaplan, J.P. Handley, A. Wlazlo, M.H. Kim, A.R. Hauser, and P.M. Schlievert. 1992. Clonal basis for resurgence of serious Streptococcus pyogenes disease in the 1980s. Lancet. 339:518-521.

3. Musser, J.M., V. Kapur, S. Kanjilal, U. Shah, D.M. Musher, N.L. Barg, K.H. Johnston, P.M. Schlievert, J. Henrichson, D. Gerlach, et al. 1993. Geographic and temporal distribution and molecular characterization of two highly pathogenic clones of Streptococcus pyogenes expressing allelic variants of pyrogenic exotoxin A (scarlet fever toxin). J. Infect. Dis. 167:337-346.

4. Chaussee, M.S., J. Liu, D.L. Stevens, and J.J. Ferretti. 1996. Genetic and phenotypic diversity among isolates of Streptococcus pyogenes from invasive infections. J. Infect. Dis. 173:901-908.

5. Cone, L.A., D.R. Woodard, P.M. Schlievert, and G.S. Tomory. 1987. Clinical and bacteriologic observations of a toxic shock-like syndrome due to Streptococcus pyogenes. N. Engl. J. Med. 317:146-149.

6. Stevens, D.L., M.H. Tanner, J. Winship, R. Swarts, K.M. Ries, P.M. Schlievert, and E. Kaplan. 1989. Severe group A streptococcal infections associated with a toxic shock-like syndrome and scarlet fever toxin A. N. Engl. J. Med. 321:1-8.

7. Burns, E.H.J., A.M. Marciel, and J.M. Musser. 1996. Activation of a 66kilodalton human endothelial cell matrix metalloprotease by Streptococcus pyogenes extracellular cysteine protease. Infect. Immun. 64:4744-4750.

8. Musser, J.M., K. Stockbauer, V. Kapur, and G.W. Rudgers. 1996. Substitution of cysteine 192 in a highly conserved Streptococcus pyogenes extracellular protease (interleukin 1B convertase) alters proteolytic activity and ablates zymogen processing. Infect. Immun. 64:1913-1917.

9. Wheeler, M.C., M.H. Roe, E.L. Kaplan, P.M. Schlievert, and J.K. Todd. 1991. Outbreak of group A streptococcus septicemia in children. J. Am. Med. Assoc. 266:533-537.

10. Talkington, D.F., B. Schwartz, C.M. Black, J.K. Todd, J. Elliott, R.F. Breiman, and R.R. Facklam. 1993. Association of phenotypic and genotypic characteristics of invasive Streptococcus pyogenes isolates with clinical components of streptococcal toxic shock syndrome. Infect. Immun. 61:3369-3374.

11. Lukomski, S., S. Sreevatsan, C. Amberg, W. Reichardt, M. Woischnik, A. Podbielski, and J.M. Musser. 1997. Inactivation of Streptococcus pyogenes extracellular cysteine protease significantly decreases mouse lethality of serotype M3 and M49 strains. J. Clin. Invest. 99:2574-2580.

12. Lukomski, S., E.H.J. Burns, P.R. Wyde, A. Podbielski, J. Rurangirwa, D.K. Moore-Poveda, and J.M. Musser. 1998. Genetic inactivation of an extracellular cysteine protease ( $\mathrm{SpeB}$ ) expressed by Streptococcus pyogenes decreases resistance to phagocytosis and dissemination to organs. Infect. Immun. 66:771-776.

13. Wessels, M.R., A.E. Moses, J.B. Goldberg, and T.J. DiCesare. 1991. Hyaluronic acid capsule is a virulence factor for mucoid group A streptococci. Proc. Natl. Acad. Sci. USA. 88:8317-8321.

14. Wessels, M.R., J.B. Goldberg, A.E. Moses, and T.J. DiCesare. 1994. Effects on virulence of mutations in a locus essential for hyaluronic acid capsule expression in group A streptococci. Infect. Immun. 62:433-441.

15. Husmann, L.K., D.-L. Yung, S.K. Hollingshead, and J.R. Scott. 1997. Role of putative virulence factors of Streptococcus pyogenes in mouse models of long-term throat colonization and pneumonia. Infect. Immun. 65:1422-1430.

16. Schrager, H., and M.R. Wessels. 1996. Hyaluronic acid capsule and the role of streptococcal entry into keratinocytes in invasive skin infection. J. Clin. Invest. 98:1954-1958.

17. Lancefield, R. 1957. Differentiation of group A streptococci with a common $\mathrm{R}$ antigen into three serological types with special reference to the bactericidal test. J. Exp. Med. 107:525-544.

18. Perez-Casal, J., M.G. Caparon, and J.R. Scott. 1992. Introduction of the M6 gene into a deleted strain of Streptococcus pyogenes restores its ability to re- sist phagocytosis. Res. Microbiol. 143:549-558.

19. Lancefield, R.C. 1962. Current knowledge of the type specific M antigens of group A streptococci. J. Immunol. 89:307-313.

20. Hollingshead, S.K., J.W. Simecka, and S.M. Michalek. 1993. Role of M protein in pharyngeal colonization by group A streptococci in rats. Infect. Immun. 61:2277-2283.

21. Moses, A.E., M.R. Wessels, K. Zalcman, S.A. Alberti, S. NatansonYaron, T. Menes, and E. Hanski. 1997. Relative contributions of hyaluronic acid capsule and $\mathrm{M}$ protein to virulence in a mucoid strain of the group A streptococcus. Infect. Immun. 65:64-71.

22. Wexler, D.E., D.E. Chenoweth, and P.P. Cleary. 1985. Mechanism of action of the group A streptococcal C5a inactivator. Proc. Natl. Acad. Sci. USA 82:8144-8148.

23. Cleary, P.P., U. Prahbu, J.B. Dale, D.E. Wexler, and J. Handley. 1992. Streptococcal C5a peptidase is a highly specific endopeptidase. Infect. Immun 60:5219-5223.

24. Berge, A., and L. Bjorck. 1995. Streptococcal cysteine protease releases biologically active fragments of streptococcal surface proteins. J. Biol. Chem. 270:9862-9867.

25. Wang, R.F., and S.R. Kushner. 1991. Construction of versatile lowcopy-number vectors for cloning, sequencing, and gene expression in Escherichia coli. Gene. 100:195-199.

26. Perez-Casal, J., J.A. Price, E. Maguin, and J.R. Scott. 1993. An M protein with a single $\mathrm{C}$ repeat prevents phagocytosis of Streptococcus pyogenes: use of a temperature-sensitive shuttle vector to deliver homologous sequences to the chromosome of S. pyogenes. Mol. Microbiol. 8:809-819.

27. Current Protocols in Molecular Biology. 1987. F.M. Ausubel, R. Brent, R.E. Kingston, D.D. Moore, J.G. Seidman, J.A. Smith, and K. Struhl, editors. J. Wiley, New York

28. O’Connor, S.P., and P.P. Cleary. 1987. In vivo Streptococcus pyogenes C5a peptidase activity: analysis using transposon- and nitrosoguanidine-induced mutants. J. Infect. Dis. 156:495-504.

29. Caparon, M.G., D.S. Stephens, A. Olsen, and J.R. Scott. 1991. Role of M protein in adherence of group A streptococci. Infect. Immun. 59:1811-1817.

30. Caparon, M.G., and J.R. Scott. 1991. Genetic manipulation of pathogenic streptococci. Methods Enzymol. 204:556-586.

31. Hynes, W.L., and J.R. Tagg. 1985. A simple plate assay for detection of group A streptococcus proteinase. J. Microbiol. Methods. 4:25-31.

32. Lancefield, R.C. 1928. The antigenic complex of Streptococcus hemolyticus. I. Demonstration of a type specific substance in extracts of Streptococcus hemolyticus. J. Exp. Med. 47:91-103.

33. Laboratory Methods in Histotechnology. 1992. E.B. Prophet, B. Mills, J.B. Arrington, and L.H. Sobin, editors. American Registry of Pathology, Washington, D.C

34. Statistical Models and Methods for Lifetime Data. 1982. J.F. Lawless, editor. J. Wiley, New York.

35. Hauser, A.R., and P.M. Schlievert. 1990. Nucleotide sequence of the streptococcal pyrogenic exotoxin type B gene and toxin relationship to streptococcal proteinase precursor. J. Bacteriol. 172:4536-4542.

36. Dougherty, B.A., and I. van de Rijn. 1994. Molecular characterization of has $A$ from an operon required for hyaluronic acid synthesis in group A streptococci. J. Biol. Chem. 269:169-175.

37. DeAngelis, P.L., J. Papaconstantinou, and P.H. Weigel. 1993. Molecular cloning, identification, and sequence of the hyaluronan synthase gene from group A Streptococcus pyogenes. J. Biol. Chem. 268:19181-19184.

38. Dale, J.B., M. Simmons, E.C. Chiang, and E.Y. Chiang. 1996. Recombinant, octavalent group A streptococcal M protein vaccine. Vaccine. 14:944-948.

39. Barker, F.G., B.J. Leppard, and D.V. Seal. 1987. Streptococcal necrotizing fasciitis: comparison between histological and clinical features. J. Clin. Pathol. 40:335-341.

40. Crater, D.L., B.A. Dougherty, and I. van de Rijn. 1995. Molecular characterization of has $C$ from an operon required for hyaluronic acid synthesis in group A streptococci. J. Biol. Chem. 270:28676-28680.

41. Crater, D.L., and I. van de Rijn. 1995. Hyaluronic acid synthesis operon (has) expression in group A streptococci. J. Biol. Chem. 270:18542-18548.

42. Wessels, M.R., and M.S. Bronze. 1994. Critical role of the group A streptococcal capsule in pharyngeal colonization and infection in mice. Proc. Natl. Acad. Sci. USA. 91:12238-12242.

43. Ji, Y., L. McLandsborough, A. Kondagunta, and P.P. Cleary. 1996. C5a peptidase alters clearance and trafficking of group A streptococci by infected mice. Infect. Immun. 64:503-510. 